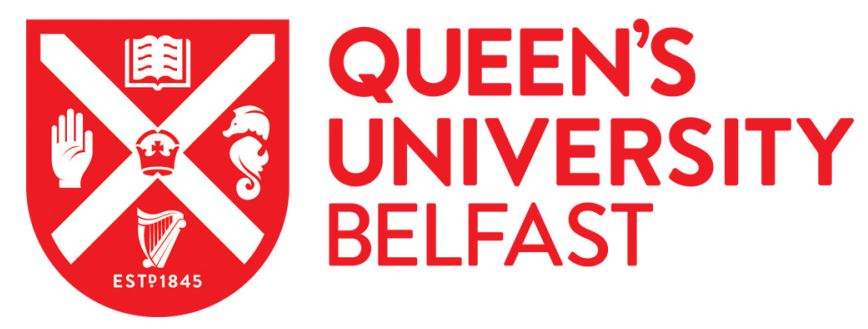

\title{
Genomic meningococcal load in the nasopharynx of children with meningococcal disease
}

Bourke, T. W., McKenna, J. P., Coyle, P. V., Fairley, D. J., \& Shields, M. D. (2016). Genomic meningococcal load in the nasopharynx of children with meningococcal disease. The Pediatric Infectious Disease Journal, 35(5), 577-579. https://doi.org/10.1097/INF.0000000000001079

\section{Published in:}

The Pediatric Infectious Disease Journal

\section{Document Version:}

Peer reviewed version

Queen's University Belfast - Research Portal:

Link to publication record in Queen's University Belfast Research Portal

\section{Publisher rights}

(C) 2016, The Authors

This is a non-final version of an article published in final form in Bourke, TW, McKenna, JP, Coyle, PV, Fairley, DJ \& Shields, MD 2016 'Genomic meningococcal load in the nasopharynx of children with meningococcal disease' The Pediatric Infectious Disease Journal, vol 35 , no. 5, pp. 577-579., 10.1097/INF.0000000000001079

\section{General rights}

Copyright for the publications made accessible via the Queen's University Belfast Research Portal is retained by the author(s) and / or other copyright owners and it is a condition of accessing these publications that users recognise and abide by the legal requirements associated with these rights.

Take down policy

The Research Portal is Queen's institutional repository that provides access to Queen's research output. Every effort has been made to ensure that content in the Research Portal does not infringe any person's rights, or applicable UK laws. If you discover content in the Research Portal that you believe breaches copyright or violates any law, please contact openaccess@qub.ac.uk. 


\section{Title Page}

Genomic meningococcal load in the nasopharynx of children with meningococcal disease

Thomas $\mathrm{W}$ Bourke $\mathrm{MD}^{1,3}$, James $\mathrm{P}$ McKenna $\mathrm{PhD}^{2}$, Peter V Coyle $\mathrm{MD}^{2,3}$, Derek J Fairley $\mathrm{PhD}^{2,3}$, Michael D Shields $\mathrm{MD}^{1,3}$

1 Royal Belfast Hospital for Sick Children, Falls Road, Belfast, United Kingdom. BT12 6BE

2 Regional Virus Laboratory, Belfast Health and Social Care Trust, Grosvenor Road Belfast, BT12 6BA

3 Centre for Infection and Immunity, Queen's University Belfast, Lisburn Road Belfast, BT9 7AE

Corresponding author:

Dr Derek J Fairley; Regional Virus Laboratory, Belfast Health and Social Care Trust, Grosvenor Road Belfast, United Kingdom. BT12 6BA

derek.fairley@belfasttrust.hscni.net

Telephone 00442890632662

Fax 00442890634803

Conflicts of interest and relevant funding:

TWB received a grant from the Health \& Social Care Research and Development Office, Public Health Agency, Northern Ireland. JPM, PVC and DJF hold share options in Hibergene Diagnostics Ltd. JPM, PVC and DJF hold patent US 8465927 
B2 related to the meningococcal LAMP assays cited in this study which is licensed to Hibergene Diagnostics Ltd. MDS has nothing to disclose.

Key words:

Meningococcal disease, Neisseria meningitidis, bacterial load

Abbreviated title:

Nasopharyngeal bacterial load in meningococcal disease

Running title:

NP meningococcal load 


\section{Abstract}

This study demonstrates the feasibility of using quantitative real time PCR to measure genomic bacterial load in the nasopharynx of children with invasive meningococcal disease and shows that these loads are exceptionally high (median $6.6 \times 10^{5}$ (Range $1.2 \times 10^{5}$ to $1.1 \times 10^{8}$ ) genome copies of Neisseria meningitidis per swab). 


\section{Introduction}

Invasive infection with Neisseria meningitidis (NM) causes meningitis and septicemia in children [meningococcal disease]. Most adults have carried meningococcus in their nasopharynx at some stage during their lives ${ }^{1}$ and most remain asymptomatic. A very small proportion progress to invasive disease.

The prevalence of meningococcal carriage is often quoted as being $\sim 10 \%$, although it should be emphasised this refers to the average carriage rate across all age groups. ${ }^{2}$ Carriage rates vary dramatically with age, with the lowest rates seen in very young children, who are at highest risk of invasive disease, and the highest rates (often in excess of $20 \%$ ) seen in late adolescence..$^{2,3}$

Public Health England (PHE) and National Institute for Health and Care Excellence (NICE) guidelines previously disagreed over the value of nasopharyngeal specimens as a diagnostic test for this infection. PHE recommend that testing of nasopharyngeal specimens may help support a clinical diagnosis alongside other signs and symptoms, and can allow identification of strains in the event of a cluster or outbreak. ${ }^{2}$ Advice not to test nasopharyngeal specimens by any method because of the risk of detecting asymptomatic carriage has recently been removed from UK NICE guidance, to bring it into line with PHE guidance. ${ }^{5}$

Two previous studies from our group demonstrate that molecular testing of nasal and throat swabs has a sensitivity of 81 to $84 \%$ and a specificity of $100 \%$ as a diagnostic test for meningococcal disease. ${ }^{6,7}$ With the recent development and licensure of novel meningococcal vaccines, their effect on reducing nasopharyngeal carriage is likely to have a major impact on their effectiveness at inducing herd protection. 
Two studies demonstrate a strong association between meningococcal DNA load in

blood at presentation and disease severity. ${ }^{8,9}$ To date, no study has attempted to quantify meningococcal DNA load in nasopharyngeal specimens using molecular testing.

Estimation of nasopharyngeal bacterial load is complicated by potential inconsistency in the sampling technique resulting in varying amounts of cellular material being obtained. Specifically, false negative results may arise from poor quality specimens containing little or no cellular material. The RNAseP gene is a proven single copy human gene. Absolute quantification of this gene using real-time TaqMan PCR can be used to accurately estimate the quantity of human DNA (and hence cells) in a clinical sample. ${ }^{10}$ This enables quality control of specimens, and can potentially also be used to 'normalise' the bacterial load data.

The aim of this study was to define the meningococcal DNA load in nasopharyngeal specimens in children with meningococcal disease.

\section{Methods}

Nasopharyngeal swabs and blood specimens were collected from children with suspected meningococcal disease as part of an ethically approved diagnostic accuracy study between November $1^{\text {st }} 2009$ and January $31^{\text {st }} 2012.7$ Nasopharyngeal specimens were obtained using rayon tipped throat swabs (Transwab, MWE, Wiltshire, UK) and floc tipped nasal swabs (Copan, Brescia, Italy). Both swabs were then placed into a single container containing $1 \mathrm{ml}$ of eNat nucleic acid transport medium (Copan, Brescia, Italy). For this study paired samples from 
children with laboratory confirmed disease [Culture of $N M$ and/or detection of $N M$ DNA from a normally sterile site; see reference 7] were analysed. Specimens were tested using ctrA and RNAseP real-time TaqMan PCR and the genomic bacterial load was estimated using external standard curve calibration. Details of the PCR assays, molecular testing protocols and calculation of standard curves is given in Supplementary Digital Content A. Requirement for fluid bolus resuscitation was used as an indicator of more severe clinical presentation.

\section{Statistical methods}

Skewed data were log transformed for statistical comparisons. Pearson's correlation coefficient and means were compared using an independent samples two tailed $t$ test. One obvious and statistically significant outlier \{linear regression RStudent $>2$ criteria (outlier) and CooksD $>0.5$ (undue influence)\} was not included in the analyses but the outlier was separately described.

Multiple regression analysis was performed using age (in days), gender, severity score (with/without fluid bolus) and copy number in blood as variables to predict copy number in the nasopharynx.

\section{Results}

21 pairs of specimens from children with laboratory confirmed meningococcal disease were analysed. 
There was a 2:1 female:male ratio (67\% female, $33 \%$ male). The age range was 6 months to 8 years 4 months (mean 2 years 10 months). Using need for fluid bolus resuscitation as a proxy for severity, 10/21 (48\%) required at least one bolus.

The nasopharyngeal specimens contained a median of $6.6 \times 10^{5}$ (Range $1.2 \times 10^{5}$ to $1.1 \times 10^{8}$ ) genome copies of meningococcus per $\mathrm{ml}$ of transport medium. As the combined nasal and throat swab were inserted into $1 \mathrm{ml}$ of medium this reflects the total amount of bacteria obtained on both swabs. The blood specimens contained a median of $9.9 \times 10^{5}$ (Range $3.7 \times 10^{4}$ to $8.2 \times 10^{7}$ ) genome copies of meningococcus per $\mathrm{ml}$ of original specimen. There was no difference in mean log copy number between nasopharyngeal and blood specimens (3.49 $\log _{10}$ copies/ml versus 3.54 $\log _{10}$ copies $/ \mathrm{ml}, \mathrm{p}=0.9$ ).

The outlier excluded from the analysis was from a patient who had an exceptionally high nasopharyngeal bacterial load $\left[1.1 \times 10^{8}\right]$ and a moderate blood bacterial load $\left[4.7 \times 10^{6}\right]$ following a short $[<6$ hours $]$ history. Without this outlier value a moderate correlation $(\mathrm{R}=0.57(95 \% \mathrm{Cl}: 0.16$ to 0.80$)$ [Figure 1]) was found between nasopharyngeal and blood meningococcal copy number.

Analysis of RNAseP in the nasopharyngeal specimens revealed a median of $2.5 \mathrm{x}$ $10^{5}$ (range $2.1 \times 10^{3}$ to $6.4 \times 10^{6}$ ) cells per $\mathrm{ml}$ of transport medium. Correcting the bacterial load for nasopharyngeal specimen quality by calculating the number of bacteria per host cell weakened the correlation between log nasopharyngeal and log blood meningococcal copy number. A strong correlation between log bacteria per 10 cells and the raw log nasopharyngeal copy number was observed (Pearson's correlation coefficient $R=0.74, p=0.001$ ) indicating that the uncorrected and corrected nasopharyngeal load are closely related. 
Children who required fluid resuscitation at the time of admission had significantly higher mean blood log copy numbers than those who did not $\left(3.90 \log _{10}\right.$ copies $/ \mathrm{ml}$ versus $3.06 \log _{10}$ copies $/ \mathrm{ml}, \mathrm{p}=0.02$ ). Nasopharyngeal log copy number also tended to be higher but this did not reach significance. The single patient who died during the study had a nasopharyngeal meningococcal copy number of $5.1 \times 10^{6}$ (seven times higher than the median) and a blood meningococcal copy number of $3.1 \times 10^{7}$ (thirty times higher than the median). This patient had a short history having gone to bed well at 22:00 and awoken in the early hours of the morning with an extensive purpuric rash.

Multiple regression analysis confirmed that copy number in blood was the only statistically significant predictor of copy number in the nasopharynx, after adjustment for age, gender and severity ( $\beta$-coefficient $0.84 ; p=0.024$ ). None of the other variables were significant, and there was no bias towards more severe clinical presentation.

\section{Discussion}

This small study is the first to demonstrate the exceptionally high nasopharyngeal loads of meningococcus in patients presenting with confirmed meningococcal disease. The bacterial load in blood is very similar to previous studies indicating that the methodology used is robust. ${ }^{8,9}$ After removal of one statistical outlier we observed a moderate correlation between nasopharyngeal and blood bacterial load. This potential correlation is based on a small data set and confirmation in a larger study is required. Multiple regression analysis identified blood load as the only statistically significant predictor of nasopharyngeal load. 
Interpretation of meningococcal load in nasopharyngeal specimens is challenging because of potential inconsistency in sampling. Analysis of RNAseP reveals that the quantity of human material obtained by a nasopharyngeal swab ranges from a few thousand to a few million cells. Despite this variation we still demonstrate very high loads, even in relatively poor quality samples. Furthermore, there is a strong correlation between the raw meningococcal load data and meningococcal load corrected for swab quality indicating that correction is probably not necessary.

In this study we only had a single specimen at a single time point and cannot describe the dynamics of meningococcal copy number or relate nasopharyngeal to blood copy number as invasive disease progresses. The demonstration of relatively high nasopharyngeal loads in some patients supports our hypothesis that molecular testing of nasopharyngeal specimens adds value to diagnostic testing for meningococcal disease. Testing of both nasopharyngeal and blood specimen by ctrA real-time TaqMan PCR (as occurs in our unit) has the potential to capture more cases. Using a molecular test to detect the ctrA gene in nasopharyngeal swabs ensures that only pathogenic (capsular) strains are detected. In contrast, culture of nasopharyngeal swabs will also recover carrier (acapsular) strains.

Novel meningococcal B vaccines targeting outer membrane vesicles may have a much less dramatic effect on carriage ${ }^{11}$ than conjugate vaccines like Men $\mathrm{C}$ which virtually eliminated carriage. It is clear that any large implementation programme will require careful monitoring of carriage and we believe that the methodology described in this study would be ideal for large scale accurate surveillance studies.

The results presented here confirms that quantitative data can be reliably obtained from nasopharyngeal swab specimens using molecular methods, and that a human 
gene target (RNAseP) can be used as an endogenous control. These data provide further evidence that molecular testing of respiratory specimens is feasible, and may give diagnostically useful information in suspected meningococcal disease. We believe that access to relatively non-invasive rapid molecular testing of nasopharyngeal specimens such as meningococcal LAMP 7,12 has potential to increase diagnosis of meningococcal disease in the early stages where nasopharyngeal loads may to be relatively higher as initial replication is taking place.

\section{Conflicts of interest and relevant funding:}

TWB received a grant from the Health \& Social Care Research and Development Office, Public Health Agency, Northern Ireland. JPM, PVC and DJF hold share options in Hibergene Diagnostics Ltd. JPM, PVC and DJF hold patent US 8465927 B2 related to the meningococcal LAMP assays cited in this study which is licensed to Hibergene Diagnostics Ltd. MDS has nothing to disclose. 


\section{References}

1. Caugant DA, Maiden MC. Meningococcal carriage and disease-population biology and evolution. Vaccine. 2009;27 Suppl 2: B64-70.

2. Cartwright KAV, Stuart JM, Jones DM, Noah ND. The Stonehouse survey: nasopharyngeal carriage of meningococci and Neisseria lactamica. Epidem. Inf. 1987; 99:591-601

3. Christensen $\mathrm{H}$, May M, Bowen L, Hickman M, Trotter CL. Meningococcal carriage by age: a systematic review and meta-analysis. Lancet Infect Dis. $2010 ; 10: 853-61$

4. Health Protection Agency Meningococcus and Haemophilus Forum. 2012. Guidance for public health management of meningococcal disease in the UK. https://www.gov.uk/government/publications/meningococcal-diseaseguidance-on-public-health-management accessed March 15th, 2015.

5. National Institute for Health and Care Excellence. 2010. NICE Guidance CG102: Bacterial meningitis and meningococcal septicemia: Management of bacterial meningitis and meningococcal septicemia in children and young people younger than 16 years in primary and secondary care. https://www.nice.org.uk/guidance/cg102 accessed March 15th, 2015.

6. Dunlop K, Coyle, P, Mitchell S et al. Molecular testing of respiratory swabs aids early recognition of meningococcal disease in children. Diagn Microbiol Infect Dis. 2011; 70: 427-34. 
7. Bourke T, McKenna J, Coyle P, Shields M, Fairley D. Diagnostic accuracy of 'loop mediated isothermal amplification' (LAMP) as a near-patient test for meningococcal disease in children; an observational cohort study. Lancet Infect Dis. 2015; 15(5):552-8

8. Hackett SJ, Guiver M, Marsh $\mathrm{J}$ et al. Meningococcal bacterial DNA load at presentation correlates with disease severity. Arch Dis Child. 2002;86:44-46.

9. Darton T, Guiver M, Naylor $S$ et al. Severity of meningococcal disease associated with genomic bacterial load. Clin Infect dis. 2009;48:587-594

10. McNees AL, White Z, Zanwar P, Vilchez R, Butel J. Specific and quantitative detection of human polyomaviruses BKV, JCV, and SV40 by real time PCR. J Clin Virol. 2005;34:52-62.

11. Bettinger JA, Deeks SL, Halperin SA, Tsang R, Scheifele DW. Controlling serogroup B invasive meningococcal disease: the Canadian perspective. Expert Rev Vaccines. 2013; 12(5):505-17

12. McKenna JP, Fairley DJ, Shields MD et al. Development and clinical validation of a loop-mediated isothermal amplification method for the rapid detection of Neisseria meningitidis. Diagn Microbiol Infect Dis. 2011;69:13744. 
Figure 1. Comparison of Neisseria meningitidis genome copy number in nasopharyngeal and blood specimens 


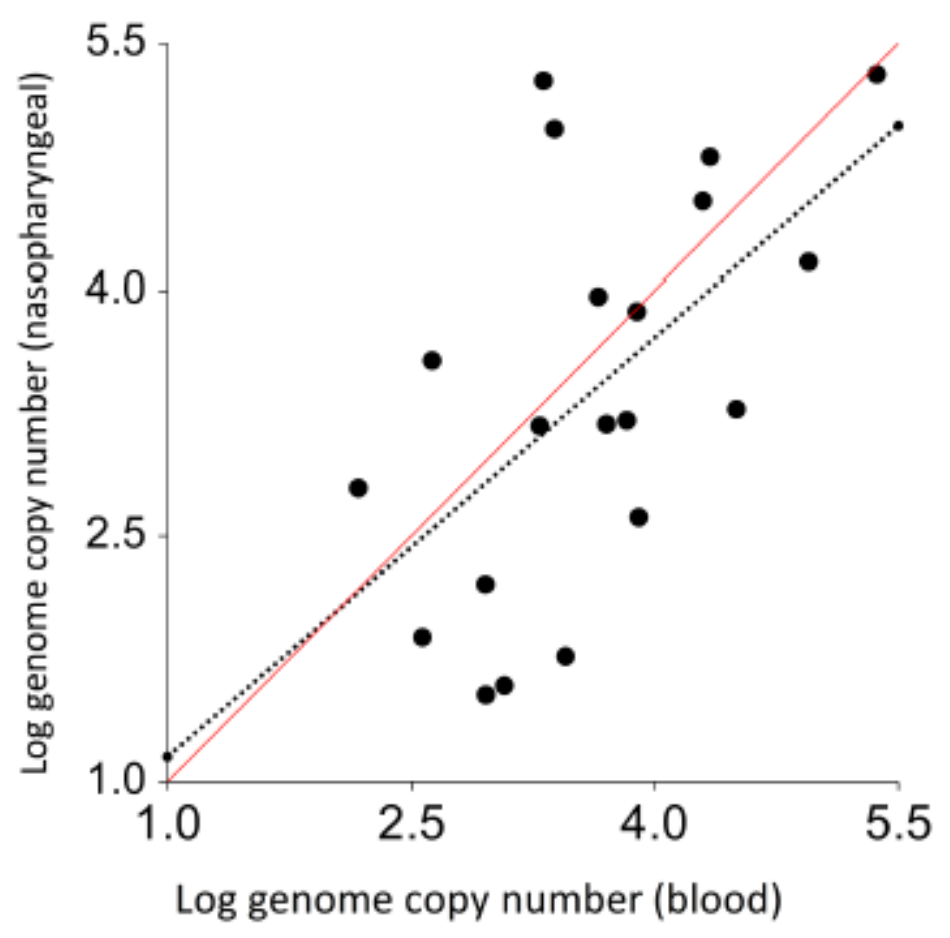




\section{Supplementary digital content A}

\section{DNA Extraction}

DNA was extracted from EDTA blood $(200 \mu \mathrm{l})$ and eNat medium $(200 \mu \mathrm{l}$, containing combined nasal and throat swabs) using a QuickGene Mini80 system and DB-S DNA kit (Fuji Corporation, Tokyo, Japan) according the manufacturers' instructions.

\section{Standard curves}

Standard curves were defined for absolute quantification using real-time TaqMan PCR. Neisseria meningitidis serogroup B (NCTC 10026) was cultured, suspended in saline and subjected to DNA extraction using QIAamp DNA Mini Kit. The genomic DNA in the extract was quantified using a NanoDrop spectrophotometer (NanoDrop Products, Wilmington, USA). The number of copies of meningococcal DNA per $\mathrm{ml}$ of extract was then estimated from the average genomic molecular weight of meningococcus B. ${ }^{1}$ For the RNAseP target $200 \mu$ of sterile EDTA blood (male) was extracted using the same extraction method. The genomic DNA in the extract was quantified using a NanoDrop. The number of human genome copies was estimated from the average molecular weight of the haploid human genome $\left(6.294 \times 10^{9}\right.$ base pairs). ${ }^{2}$ Tenfold serial dilutions of the meningococcal and human DNA extracts were then prepared and tested by ctrA and RNAseP real-time TaqMan PCR respectively [see below]. Standard curves were constructed using "trimmed mean" values from 5 replicates (mean of 3 central results from each replicate set). This gives a more robust measure of central tendency than the arithmetic mean. ${ }^{3}$ 
PCR assays

PCR assays used Invitrogen Platinum ${ }^{\circledR}$ Quantitative PCR SuperMix-UDG (Life Technologies Ltd., Paisley, UK). Primers and a TaqMan ${ }^{\circledR}$ probe to detect the meningococcal ctrA gene were used as described previously. ${ }^{4} \mathrm{An}$ additional reverse primer (5'-TTGCCGCGGATTGGCCACCA-3') was used ${ }^{5}$ to ensure that strains with known mutations in the ctrA gene could be reliably detected. ${ }^{6,7}$ Primers and probe to detect RNAseP were used as described by the Centre for Disease Control, 2009 [RNAseP F: 5'- AGA TTT GGA CCT GCG AGC G -3'; RNAseP R: 5'- GAG CGG CTG TCT CCA CAA GT -3'; RNAseP P: 5'-FAM - TTC TGA CCT GAA GGC TCT GCG CG -TAMRA 3']

PCR assays were run on a LightCycler ${ }^{\circledR}$ 480Il real-time PCR system (Roche Diagnostics Ltd., Burgess Hill, UK) using the following thermal cycling protocol: $50^{\circ} \mathrm{C}$ (10 minutes); $95^{\circ} \mathrm{C}$ (2 minutes); 45 cycles of $95^{\circ} \mathrm{C}$ (15 seconds) and $60^{\circ} \mathrm{C}(30$ seconds).

All analysis was conducted on a single plate to avoid inter-assay variation. DNA copy number per $\mu$ of extract for each specimen was calculated using the standard curves. Meningococcal bacterial load per $\mathrm{ml}$ of blood and meningococcal load and number of human cells per $\mathrm{ml}$ of transport medium were than calculated.

References

1. Parkhill J, Achtman M, James $K D$ et al. Complete DNA sequence of a serogroup A strain of Neisseria meningitidis Z2491. Nature. 200;6777:502-6. 
2. Lander ES, Linton LM, Birren B et al. "International Human Genome Sequencing Consortium. Initial sequencing and analysis of the human genome". Nature. 2001;409(6822) 860-921.

3. Tukey JW, McLaughlin DH. Less vulnerable confidence and significance procedures for location based on a single sample: Trimming/winsorisation 1. The Indian Journal of Statistics, Series A. 1963;25:331-352.

4. Corless CE, Guiver M, Borrow R, Edwards-Jones V, Fox A Kaczmarski EB. Simultaneous detection of Neisseria meningitidis, Haemophilus influenzae, and Streptococcus pneumoniae in suspected cases of meningitis and septicemia using real-time PCR. J Clin Micro. 2001;39:1553-8.

5. Guiver M, Corless CE, Marsh WJ et al. Modifications to a Published ctrA PCR Assay for the Improved Non-Culture Confirmation of Meningococcal Disease in England and Wales. Poster presented at Meningitis and Septicaemia in Children and Adults, Royal Society of Medicine, London, UK, 8 to 9 November 2011. http://meningitis.org/assets/x/53939

6. Jaton K, Ninet B, Bille J, Greub G. False-Negative PCR Result Due to Gene Polymorphism: the Example of Neisseria meningitidis. J Clin Micro. 2010;48:4590-1.

7. Cavrini F, Liguori G, Andreoli A, Sambri V. Multiple Nucleotide Substitutions in the Neisseria meningitidis Serogroup C ctrA Gene Cause False-Negative Detection by Real-Time PCR. J Clin Micro. 2010;48:3016-8. 